\title{
Comparative Proteomic Analysis on Chloroplast Proteins Provides New Insights Into the Effects of Low Temperature in Sugar Beet
}

Jiali Long

Heilongjiang University

Wang Xing

Heilongjiang University

Yuguang Wang

Heilongjiang University

Zedong Wu

Heilongjiang University

Wenjing Li

Heilongjiang University

Yi Zou

Heilongjiang University

Jiaping Sun

Heilongjiang University

Zhi Pi ( 2018060@hlju.edu.cn )

Heilongjiang University https://orcid.org/0000-0002-5055-9035

Fushun Zhang

Heilongjiang University

Original Article

Keywords: Sugar beet, low temperature stress, chloroplast, proteome

Posted Date: October 18th, 2021

DOI: https://doi.org/10.21203/rs.3.rs-965169/v1

License: (c) (i) This work is licensed under a Creative Commons Attribution 4.0 International License.

Read Full License 


\section{Abstract}

Background: Low temperature, which is one of the main environmental factors that limits geographical distribution and sucrose yield, is a common abiotic stress during the growth and development of sugar beet. As a regulatory hub of plant response to abiotic stress, activity in the chloroplasts is related to many molecular and physiological processes, particularly in response to low temperature stress.

Results: The contents of chlorophyll (Chl) and malondialdehyde (MDA), relative electrical conductivity (REL), and superoxide dismutase (SOD) activity were measured. The results showed that sugar beet could manage low temperature stress by regulating the levels of Chl, REL and MDA, and the activity of SOD. The physiological responses indicated that sugar beets respond positively to low temperature treatments and are not significantly damaged. Moreover, to determine the precise time to response low temperature in sugar beet, well-known abiotic stresses-responsive transcript factor family, namely DEHYDRATION RESPONSIVE ELEMENT BINDING PROTEIN (DREB), was selected as the marker gene. The results of phylogenetic analyses showed that $B V D R E B A 1$ and $B V D R E B A 4$ were in the same branch as the cold- and drought-responsive AtDREB gene. In addition, the expression of BVDREBs reached its maximum level at $24 \mathrm{~h}$ after low temperature by RNA-Seq and qRT-PCR analysis. Furthermore, the changes in chloroplast proteome after low temperature at $24 \mathrm{~h}$ were detected using a label-free technique. A total of 416 differentially expressed proteins were identified. GO enrichment analysis showed that $16 \mathrm{GO}$ terms were significantly enriched, particularly chloroplast stroma, chloroplast envelope, and chloroplast thylakoid membrane. It is notable that the transport of photosynthetic proteins (BvLTD, BVTOC100, and Toc-Tic complex), the formation of starch granules (BvPU1, BvISA3, and BvGWD3) and the scavenging of reactive oxygen species (BvCu/Zn-SOD, BvCAT, BvPrx, and BvTrx) were the pathways used by sugar beets to respond to low temperatures at an early stage.

Conclusions: These results provide a preliminarily analysis of how chloroplasts of sugar beet respond to low temperature stress at the translational level and provide a theoretical basis for breeding low temperature resistant varieties of sugar beet.

\section{Background}

Sugar beet (Beta vulgaris L.) is one of the most important sugar crops in the world, accounting for approximately 30\% of global sugar production (Mutasa-Gottgens et al. 2012; Porcel et al. 2018; Xing et al. 2020). In China, the main planting areas are concentrated in three regions, namely Inner Mongolia, Xinjiang and Heilongjiang. In these areas, low temperature is a common abiotic stress in plant growth and development, which is one of the main environmental factors that limits crop yield and geographical distribution (Liu et al. 2019). During the vegetation period, the production of sugar beet is limited by latespring frost and early autumn snow (Kaya and Kulan 2020). In particular, when seeds or seedlings were exposed to freezing temperatures at early developmental stages, the germination rate, survival rate and sucrose yield are severely restricted (Moliterni et al. 2015). Therefore, it is essential for sugar beet 
breeding to study the regulation of low temperature in its growth and development and improve tolerance to low temperatures.

Chloroplasts are essential organelles that determine how the photosynthesis of green plants perceive low temperature stress signals through membranes and photoreceptors. Previous studies have shown that plants experience a series of physiological and cellular regulatory activities under low temperatures, including alterations to calcium signaling, membrane structure and photosynthesis (Gan et al. 2019). Usually, the first type of metabolism to be affected is low temperature photosynthesis (Kočová et al. 2009). A rapid decline in growth at low temperatures severely inhibits photosynthesis in a number of plant species (Goulas et al. 2006). Under low temperature, the enzyme involved in the light reaction is more stable than that of the dark reaction, causing the photoinhibition of photosystem I and sometimes II and the production of reactive oxygen species (ROS) (Kenchanmane Raju et al. 2018). An excessive accumulation of ROS can damage the cell membrane system, produce malondialdehyde (MDA), cause electrolyte leakage in cells, and results in the increased electrical conductivity of plants (Farnsworth et al. 2012). Multiple types of antioxidant enzymes are expressed in response to low temperature to alleviate ROS damage (An et al. 2012; Cao et al. 2011; Kenchanmane Raju et al. 2018; Wen et al. 2019). It has been reported that cold-resistant species have more efficient antioxidant systems than sensitive species to protect the plants from ROS (Kočová et al. 2009). In addition, photosynthesis can also be enhanced by regulation of the abundance of photosynthesis-related proteins and the accumulation of starch grains and unsaturated fatty acids in chloroplasts under low temperature stress, thereby improving the cold resistance of plants (Gan et al. 2019; Popov and Astakhova 2021).

A proteomics analysis is a powerful tool to use to comprehend which proteins are present in specific tissue under abiotic stresses (Agrawal et al. 2015). In previous studies, totals of 23 and 27 droughtresistant proteins were identified from sensitive and drought-tolerant cultivars, respectively (Wang et al. 2017). Moreover, 75 proteins changed significantly under salt stress (Yang et al. 2013), with a predominance of proteins related to photosynthesis, metabolism, and stress and defense (Wang et al. 2017; Yang et al. 2013). However, the response of the chloroplast proteome to low temperature has not been studied in sugar beet. In this study, we utilized label-free quantitative proteomic analysis to explore the changes in chloroplast proteome at low temperature. The identification of functional proteins related to low temperature resistance provides a theoretical basis to further understand the mechanisms of cold tolerance and learn to breed a variety of sugar beet that is resistance to cold.

\section{Materials And Methods}

\section{Plant materials and low temperature treatment}

Sugar beet seeds brought from KWS Company were sown in pots that contained sterilized vermiculite. After germination, the seedlings were transferred to hydroponic culture in a Hoagland nutrient solution at $\mathrm{pH} 5.8$ and grown in a growth chamber at $25 \pm 2{ }^{\circ} \mathrm{C}, 140 \mu \mathrm{mol} \mathrm{m} \mathrm{m}^{-2} \mathrm{~s}^{-1}$ light intensity and a $14-\mathrm{h} / 10-\mathrm{h}$ photoperiod. After 21 days, low temperature treatments $\left(4^{\circ} \mathrm{C}\right)$ were performed in a light incubator using 
the light conditions described above. The leaves of the sugar beet plants were sampled at $0,3,6,12,24$, $36,48,72$ and $120 \mathrm{~h}$ of low temperature treatment, after which they were flash-frozen in liquid nitrogen and stored at $-80^{\circ} \mathrm{C}$ for further analysis. Three biological replicates were independently treated for each mock and low temperature treatment.

\section{Chlorophyll content}

The content of chlorophyll (Chl) was determined as described by Fargašová (2010). The leaf samples $(0.2 \mathrm{~g})$ were macerated and ground in $2-3 \mathrm{~mL} 95 \%$ ethanol. The tissues were grown further with $10 \mathrm{~mL}$ $95 \%$ ethanol until they became white. After standing for $5 \mathrm{~min}$, it was filtered. The volume was fixed to 25 $\mathrm{mL}$ with $95 \%$ ethanol. The absorbance of the extract was then measured at $470 \mathrm{~nm}, 649 \mathrm{~nm}$ and $665 \mathrm{~nm}$. The content of $\mathrm{Chl}$ content was calculated using the following formulae:

$C_{a}=13.95 A_{665}-6.88 A_{649}$

$C_{b}=24.96 A_{649}-7.32 A_{665}$

Chl content $(\mathrm{mg} / \mathrm{g})=\mathrm{C}_{\mathrm{c}} \times \mathrm{V} / \mathrm{W}$

$\mathrm{C}_{\mathrm{a}}$ and $\mathrm{C}_{\mathrm{b}} \mathrm{C}_{\mathrm{c}}$ are the concentrations of chlorophyll a and chlorophyll $\mathrm{b}$, respectively $(\mathrm{mg} / \mathrm{L}) ; \mathrm{V}$ is the total volume of the extract $(\mathrm{mL})$, and $\mathrm{W}$ is the fresh weight of the sample $(\mathrm{g})$.

\section{Relative electrical conductivity measurement}

Leaf fragments $(0.5 \mathrm{~g})$ were sampled by hole puncher and placed in a test tube that contained $10 \mathrm{~mL}$ of deionized water. After shaking in a $25^{\circ} \mathrm{C}$ water bath for $2 \mathrm{~h}$, the conductivity of the solution was measured and recorded as Lt. After the determination, the test tubes were boiled for 20 min in a thermostatic water bath and cooled to $25^{\circ} \mathrm{C}$. The conductivity of extraction solution was determined after stirring and recorded as Lo. The relative electrical conductivity (REL) was calculated using the following formula: REL (\%) = Lt/Lo × 100\% (Bao et al. 2020).

\section{MDA content}

The content of malondialdehyde (MDA) was determined using thiobarbituric acid (TBA) as previously described (Wang et al. 2018). The leaf samples $(0.5 \mathrm{~g})$ were homogenized in $5 \%$ TBA and centrifuged at $3000 \mathrm{~g}$ for $10 \mathrm{~min}$. The supernatant was mixed with the same amount of $0.67 \%(\mathrm{w} / \mathrm{v})$ TBA and cooled to room temperature after 30 minutes of boiling. The supernatant was centrifuged again at $3000 \mathrm{~g}$ for 10 min. The absorbance at $450 \mathrm{~nm}, 532 \mathrm{~nm}$ and $600 \mathrm{~nm}$ was measured, and MDA content were calculated by the formulae:

MDA content $(\mu \mathrm{mol} / \mathrm{g})=\left[6.45\left(\mathrm{~A}_{532}-\mathrm{A}_{600}\right)-0.56 \mathrm{~A}_{450}\right] \times \mathrm{V} \div \mathrm{W}$

$V$ is the volume of the extract solution $(\mathrm{mL})$, and $\mathrm{W}$ is the fresh weight of the sample $(\mathrm{g})$. 


\section{SOD measurement}

Seedling samples $(0.5 \mathrm{~g})$ were homogenized in $4 \mathrm{ml}$ of $50 \mathrm{mmol} / \mathrm{L}$ phosphate buffer $(\mathrm{pH} 7.8)$ on the ice. The homogenate was centrifuged at $12,000 \mathrm{~g}$ for 20 minutes at $4{ }^{\circ} \mathrm{C}$, and the supernatant was used as the source of superoxide dismutase (SOD). The assay mixture $(3 \mathrm{~mL})$ contained $14.5 \mathrm{mM}$ methionine, 3 $\mathrm{mM}$ EDTA-Na $2,2.25 \mathrm{mM} \mathrm{NBT}, 60 \mu \mathrm{M}$ riboflavin and $40 \mu \mathrm{L}$ of enzyme extract. The tubes were shaken while they were incubated for 20 min under a $40-\mathrm{W}$ fluorescent lamp at $25^{\circ} \mathrm{C}$. The absorbance of the extract at $560 \mathrm{~nm}$ was measured with non-illuminated samples as the blanks. The SOD activity was expressed in units $(50 \%$ NBT inhibition $=1$ unit $) \min ^{-1} \mathrm{~g}^{-1}$ of tissue.

SOD activity $(\mathrm{u} / \mathrm{g} F \mathrm{~F})=[($ Ack-AE $) \times \mathrm{V}] /(1 / 2 \mathrm{Ack} \times \mathrm{W} \times \mathrm{Vt})$

Ack and $A E$ were the absorbance of the reference tube and sample tube, respectively; $V$ was the total volume of sample solution $(\mathrm{mL})$; Vt was the volume of enzyme solution for determination $(\mathrm{mL})$, and W was the fresh weight of the sample (g).

\section{Screening of candidate BVDREBs}

AtDREBs protein sequences were downloaded from the TAIR database (www.arabidopsis.org). Potential homologous genes were screened from the sugar beet proteome database (bvseq.boku.ac.at) using the BLASTP program with an E-value less than $10 \mathrm{E}^{-5}$ and a bit score $>100$. Subsequently, a sequence alignment was performed between the AtDREBs gene and homologous genes using Cluster Omega (Boyce et al. 2015). The VT + F + I + G4 model was then selected based on the results of ModelFinder software. Finally, the phylogenetic trees were performed by lqtree software (Minh et al. 2020) using maximum likelihood and visualized by EvolView (Zhang et al. 2012).

\section{Analysis of the pattern expression of BVDREBs}

Total RNA was isolated from the young leaf tissues $(100 \mathrm{mg})$ of sugar beet using RNA-easy Isolation Reagent (Vazyme, Nanjing, China) according to the manufacturer's instructions. RNA concentrations and purity $\left(\mathrm{OD}_{260 / 280}\right)$ were measured with a NanoDrop 2000c, and their integrity was assessed using $1 \%$ agarose gel electrophoresis. DNase I and PrimeScript RT reagent kits (Takara, Dalian, China) were used to eliminate the genomic DNA and prepare the first-strand CDNA, respectively. Quantitative real-time reverse phase-PCR (qRT-PCR) was performed in TB Green premix Ex Taq (Takara, Dalian, China) using the Mx3000P real-time PCR system with three biological replications based on previous experiments ( $\mathrm{Pi}$ et al. 2020). The primers for BVDREBs were designed using Primer-BLAST, and BVGAPDH was used as an internal control (Table S1). The relative levels of gene expression were calculated using the $2^{-\triangle \triangle C T}$ method.

\section{Protein extraction and enzymolysis}


The sugar beet chloroplast proteins were extracted from seedling leaves using a Minute Chloroplast Isolation Kit (Invent Biotechnologies, Plymouth, USA) following the manufacturer's instructions. Briefly, the leaves $(200 \mathrm{mg})$ were submerged in buffer $A$ in a microcentrifuge tube and pulverized with a plastic pestle. Pre-cooled buffer $B$ was added to resuspend the precipitate after centrifugation. Then, the green precipitate of ready-for-use chloroplasts were collected. Protein extracts were lysed with SDT lysis buffer and separated by $12.5 \%$ SDS-PAGE. Protein enzymolysis was performed as reported by Coleman et al. (2017) using $300 \mu \mathrm{g}$ protein per sample for filter-aided sample preparation and desalination on a C18 cartridge (Coleman et al. 2017). The filtrate was subjected to freeze-dry vacuuming and redissolved in an aqueous solution of $0.1 \%$ formic acid (FA). Part of the filtrate was subjected to high performance liquid chromatography-mass spectrometry (LC-MS/MS) analysis.

\section{LC-MS/MS measurement and analysis}

Nanoflow reversed-phase LC separation was conducted on an EASY-nLC 1200 system. The mobile phase was composed of solvent $A\left(99.9 \% \mathrm{H}_{2} \mathrm{O}\right.$ and $\left.0.1 \mathrm{FA}\right)$ and solvent $\mathrm{B}\left(14.9 \% \mathrm{H}_{2} \mathrm{O}, 85 \%\right.$ acetonitrile, and $0.1 \%$ FA). The LC separation was conducted using the following gradient: solvent $B$ was started at $5 \%$ for 2 min at a flow rate of $300 \mathrm{~nL} / \mathrm{min}$ and then increased to $40 \%$ over $100 \mathrm{~min}$. Solvent B was subsequently rapidly increased to $100 \%$ in 8 min and maintained for 12 min before $100 \%$ solvent A was used for column equilibration. Electrospray MS and MS data were acquired on a Q-Exactive HF-X mass spectrometer. All the analyses were performed in the positive ion mode using a nano-electrospray ion source. Full scan MS spectra ( $\mathrm{m} / \mathrm{z} 300-1800)$ were acquired at 60,000 resolution and an automatic gain control target value of $3 \times 10^{6}$ charges. For the top 20 precursor ions, high-resolution MS2 spectra were acquired in the Orbitrap with a maximum injection time of $50 \mathrm{~ms}$ at 15,000 resolution (isolation window $1.6 \mathrm{~m} / \mathrm{z}$ ), an AGC target value of $1 \times 10^{5}$ and normalized collision energy of $28 \%$.

\section{Proteomic data processing}

The raw MS files were processed by MaxQuant and searched against the protein database (Beta_vulgaris.RefBeet-1.2.2.pep.all). Trypsin was set as the primary digest reagent, and carbamidomethyl as a fixed modification. The maximum number of missed cleavages was set to 2 . Both peptides and proteins were filtered to a specified false discovery rate $(F D R)<0.01$. To determine which proteins are transcribed and translated by chloroplast DNA, all of the protein sequences identified by MS were searched against the protein database using BLASTP, and the threshold of E-value and score were set as E-value $<10 \mathrm{E}^{-5}$ and score $>50$. Proteins with the absolute value of the log2Ratio $(24 \mathrm{~h} / \mathrm{ck})>1.5$ and $P$-values $<0.05$ were considered to be significant differentially expressed proteins (DEPs). Finally, eulerAPE was used to compare the DEPs and draw the Venn diagram (Micallef et al. 2014). Moreover, all of the protein sequences were searched against the sugar beet chloroplast genome (SMRT sequencing only de novo assembly of the sugar beet (Beta vulgaris) chloroplast genome) using BLASTP.

\section{GO enrichment analysis of DEPs}


Gene Ontology (GO) enrichment analysis was performed using AgriGo with default values (Du et al. 2010). References for the proteome annotation of beet were downloaded from PLAZA 4.0 Dicots (https://bioinformatics.psb.ugent.be/plaza/versions/plaza_v4_dicots/).

\section{Results}

\section{Physiological responses to low temperature stress in sugar beet}

Compared with the controls, there was no significant change in the Chl content within $48 \mathrm{~h}$ of low temperature treatment. After $72 \mathrm{~h}$ of low temperature treatment, the Chl content increased significantly to $20 \%$ (Fig. 1a). No significant change occurred in the damage of plasma membranes with REL of all the samples compared with the controls (Fig. 1b). However, a significant increase of MDA content was observed after $12 \mathrm{~h}$ of low temperature treatment (Fig. 1c). The activity of SOD increased and then reached its highest level after $24 \mathrm{~h}$ (Fig. 1d). These findings suggest that sugar beet responded positively within $24 \mathrm{~h}$ of low temperature treatment and was not significantly damaged in chloroplast.

\section{Analysis of the expression pattern of BVDREBs genes}

To profile the transcriptional response, BVDREBs, orthologous genes in Arabidopsis thaliana that act essential regulators in cold response pathway, were identified and selected as marker genes (Bo et al. 2007). A total of 73 homologous genes were identified in sugar beet using bidirectional BLAST searches. A phylogenetic analysis of these 73 homologous genes showed that 15 clades that contained the DREBA1, DREB-A4 and soloist subfamilies were resolved (Fig. 2). The DREB-A1 subfamily played an important role in low temperature stress. As physiological drought is often accompanied by low temperature, the adjacent DREB-A4 subfamily that responded to drought was also considered as candidate genes.

There were four sugar beet genes in the same branch as that of the AtDREB-A1 gene. However, only BV3_066590_ignp (BVDREBA1) was significantly up-regulated in four candidate genes after low temperature treatment based on the transcriptome data. Among of DREB-A4 subfamily genes, the Bv2_032310_xjoh (BvDREBA4) gene also responds to low temperature (Fig. 3a). Subsequently, the dynamic changes of expression of $B V D R E B A 1$ and $B v D R E B A 4$ were measured by qRT-PCR. The results indicated that BVDREBA 1 and $B V D R E B A 4$ changed significantly within $3 \mathrm{~h}$ of the low temperature treatment and reached their peak after $24 \mathrm{~h}$ of treatment with low temperature. The level of expression of BVDREBA1 and BVDREBA4 began to gradually decease, and the level of expression after $48 \mathrm{~h}$ of low temperature treatment was significantly lower than that after $24 \mathrm{~h}$ of low temperature treatment (Fig. 3b, c).

\section{Chloroplast proteome identification}

Based on physiological and transcriptional changes, sugar beets that had been treated by $24 \mathrm{~h}$ of low temperature, were selected as the samples to detect chloroplast proteomes in subsequent studies. After extraction of chloroplast protein (CK, $24 \mathrm{~h}$ ), only protein samples with a highly abundant Ribulose-1,5- 
bisphosphate carboxylase/oxygenase (RuBisCo), as characteristic protein in chloroplasts, observed near $60 \mathrm{kDa}$ and without obvious protein degradation was used for subsequent MS analysis. A total of 103,562 peptides (CK, 24 h) were identified by LC-MS/MS, with 16,423 unique peptides that corresponded to 3,420 proteins. Moreover, it was notable that approximately 10,677 to 14,102 unique peptides that corresponded to 2,887 to 3,169 proteins were identified in each sample (Fig. 4a, b). The Pearson correlation coefficients between three biological repeats were $>0.97$ in each group (Fig. S1a). The log2 values of peptide intensity in each sample ranged from 25 to 30, and the peptides with different signal intensities had a normal distribution (Fig. S1b). That finding demonstrated that not only are the biological samples in the group reproducible but also that the MS is highly stable.

A t-test was performed to investigate DEPs in response to low temperatures. The ratio fold changes $\log 2(24 \mathrm{~h} / \mathrm{ck})>1.5$ and $\mathrm{p}$-values $<0.05$ were regarded as the thresholds for screening the DEPs between the $\mathrm{CK}$ and $24 \mathrm{~h}$ (Fig. 4C). A total of 416 DEPs were identified, including 91 up-regulated proteins and 111 down-regulated proteins, and 214 proteins were specifically expressed in the CK or $24 \mathrm{~h}$ (Fig. 4d, Table S2). An analysis of the specific expression proteins indicated that 164 up-regulated and 50 downregulated DEPs were detected. Among the up-regulated and down-regulated proteins, the expression of 33 and 24 proteins changed by more than 2 -fold, respectively.

\section{Identification of proteins encoding from chloroplast DNA}

According to the sugar beet chloroplast genome (SMRT sequencing only de novo assembly of the sugar beet (Beta vulgaris) chloroplast genome), a total of nine proteins $(0.3 \%)$ encoded by the chloroplast genome were identified by BLASTP (Fig. S2a). They were primarily divided into three types, namely ribosomal proteins (5), RNA polymerases (3) and an ATP synthase (1) (Fig. S2b). Among them, there were three DEPs, including two ribosomal proteins and one ATP synthase, accounting for $0.7 \%$ of the DEPs (Fig. S2c, d). Additionally, the expression of these proteins has a high fold change in response to low temperature treatment. At $24 \mathrm{~h}$ of low temperature treatment, the ATP synthase protein was up-regulated 23-fold, and the protein of two ribosomes was up-regulated 6-fold and 2-fold, respectively. Large changes in protein abundance suggest that chloroplast DNA-encoded proteins also play an important role in response to low temperature or cold acclimation of sugar beet.

\section{GO enrichment analysis of DEPs}

To explore the biological functions of the low temperature responsive proteins, we used AgriGO to analyze the DEPs at low temperature responsive stages. A total of $143 \mathrm{GO}$ terms were significantly enriched, of these, including 47 biological process, three molecular function and 93 cellular components. Based on the relationship between the directed acycline praph and the false discovery rate (FDR), we screened 16 significantly enriched GO terms that play a major role in response to the low temperature of chloroplasts in sugar beets (Fig. 5).

There were eight significantly enriched $\mathrm{GO}$ terms in the biological process, among them, the most significantly enriched GO term was translation (GO:0006412), and its FDR value was 2.1 $1 \mathrm{E}^{-5}$. Response to 
cold (G0:0009409), response to cadmium ion (G0:0046686) and small molecule metabolic process (G0:0044281) followed with FDR values of $1.4 \mathrm{E}^{-4}, 2.2 \mathrm{E}^{-4}$ and $6.8 \mathrm{E}^{-4}$, respectively. Significantly enriched $\mathrm{GO}$ terms reflect that sugar beet chloroplasts initiate a response to low temperature through $\mathrm{Ca}^{2+}$ signaling and translate more novel proteins that are involved in the resistance to cold. RNA binding (GO:0003723), translation factor activity (G0:0008135) and structural molecule activity (GO:0005198) were significantly enriched in the molecular function, with FDR values of $0.022,0.022$ and 0.033 , respectively. Five $\mathrm{GO}$ terms in the cell component were significantly enriched. The FDR values of chloroplast stroma (G0:0009570), chloroplast envelope (GO:0009941) and chloroplast thylakoid membrane (G0:0009535) were $3.3 \mathrm{E}^{-24}, 3.1 \mathrm{E}^{-16}$ and $2.3 \mathrm{E}^{-13}$, respectively, which were the most significant in all of the $\mathrm{GO}$ terms. This finding indicates that the chloroplast stroma, chloroplast envelope and chloroplast thylakoid membrane are the primary components of low temperature response.

The functions of the DEPs located on chloroplast components were classified in more detail. A total of 112 DEPs were involved in the low temperature response in chloroplast stroma (G0:0009570), chloroplast envelope (G0:0009941) and chloroplast thylakoid membrane (G0:0009535) (Fig. 6a).

The number of proteins related to substance metabolism and protein synthesis was the largest in the chloroplast stroma (G0:0009570), with 18 and 17, accounting for $26.9 \%$ and $25.4 \%$, respectively (Fig. $6 \mathrm{~b})$. Five proteins were up-regulated, and 13 proteins were down-regulated in substance metabolism. These types of substance metabolism involved the pentose phosphate pathway, starch metabolism and synthesis. In addition, the DEPs related to protein synthesis primarily included the 50 S large subunit and 30S small subunit that form ribosomes, and protein translation and folding related proteins, such as tRNA aminotransferase, translation elongation factor and peptidyl prolyl cis-trans isomerase. Four ribosomal proteins significantly increased after $24 \mathrm{~h}$ of low temperature treatment. Moreover, there were also a large number of proteins related to stress defense (9) and light reactions (8), accounting for $13.4 \%$ and $11.9 \%$, respectively. In stress and defense, Cu/Zn-SOD, CAT, peroxiredoxin (Prx) and thioredoxin (Trx) were involved to activate the $\mathrm{H}_{2} \mathrm{O}_{2}$ signaling-related proteins and ROS scavenging.

The number of transport-related proteins was the largest chloroplast envelope in (G0:0009941). They totaled 12, accounting for $22.2 \%$, primarily including Toc-Tic complexes, glucose transporters, aquaporins, and ADP/ATP transport among others (Fig. 6c). Protein synthesis followed with 10 DEPs, accounting for $18.5 \%$, including the $50 \mathrm{~S}$ large subunit and $30 \mathrm{~S}$ small subunit. There were seven unknown proteins accounting for $13 \%$, which could be related to the low temperature response. The role of these proteins in low temperature response merit additional study in the future.

The main low temperature responsive proteins in chloroplast thylakoid membrane (G0:0009535) were concentrated in the light reaction and included 13 proteins, accounting for $38.2 \%$ (Fig. 6d). These proteins are involved photosystem I (PS I), photosystem II (PS II), quinone oxidoreductase, and ATP synthase. Additionally, nine unknown proteins still responded to low temperature stress, accounting for $26.5 \%$. The function and relationship with the light reaction still merit further study. 


\section{Molecular mechanisms of the chloroplast that underlie low temperature in sugar beet}

This analysis revealed the following processes that sugar beets use to manage low temperature stress in chloroplast of sugar beet (Fig. 7). After low temperature treatment for $24 \mathrm{~h}$, a large number of proteins significantly increased in the photosynthetic system. Notably, most photosynthetic proteins were expressed in the nuclear genomes and then entered the chloroplasts through the Toc-Tic complex, including BVTOC100, under the control of BVLTD. In additional, chloroplast genes were also induced by low temperature to initiate transcription and translation. ATP synthase was highly expressed under the induction of chloroplast ribosomal protein. The a subunit in particular was up-regulated 23-fold. An increased abundance of these proteins may lead to an increase in glucose content in chloroplasts. These glucose molecules can be used as osmotic regulators by transportation outside of the chloroplasts via BvGlcT. Moreover, it can also be synthesized as amylose. Amylose is further metabolized to amylopectin under the action of enzymes, such as BvPU1. The abundance of starch degradation-related proteins (BvISA3 and BvGWD3) decreased significantly, indicating that low temperature could induce the formation of starch granules in sugar beet chloroplasts. Finally, to protect the ROS generated through photosynthetic electron transport, the ROS scavenging system composed of BvCu/Zn-SOD and BvCAT was also induced by low temperature. The up-regulation of BvPrx and BvTrx protein not only enhanced the removal of $\mathrm{H}_{2} \mathrm{O}_{2}$ but were also involved in the oxidation of signaling proteins, such as transcription factors and phosphatase, enabling signaling via the transmission of $\mathrm{H}_{2} \mathrm{O}_{2}$ to the nucleus and upregulating the expression of stress and defense-related proteins.

\section{Discussion}

The chloroplast is the main place of plant photosynthesis and is also very sensitive to ambient temperature. Low temperature stress can significantly inhibit the activity of chloroplast proteins, interfere with photosynthetic electron transport and photosynthetic phosphorylation, cause the accumulation of ROS, and finally cause oxidative damage (Calzadilla et al. 2019). Relatively, short-term or intermittent low temperature stress increases the resistance of plants to low temperature, a phenomenon known as cold acclimation (Gerber et al. 2021). In A. thaliana, AtDREBs are important transcription factors that regulate cold acclimation and are involved in gene activation and the inhibition of $\mathrm{Ca}^{2+}$ and hormone signals and carbon metabolism, respectively (Zhao et al. 2016). The results of this study showed that low temperatures could induce the expression of BVDREB genes, reaching the highest level after $24 \mathrm{~h}$, suggesting that cold acclimation was activated. To explore which proteins were involved in the cold acclimation of chloroplasts in sugar beet, the proteome was detected using the Label-free technique before and after treatment with low temperature. A total of 416 proteins was found to be significantly affected by low temperature. An AgriGO analysis showed that proteins from the chloroplast thylakoid membrane, envelope and stroma were the most sensitive to low temperature. In these compartments, the proteins involved in photosynthesis, starch metabolism, chloroplast protein translation, protein transport and antioxidant processes should be closely related to the cold acclimation of sugar beet.

\section{Effect of low temperature on chloroplast thylakoid membrane proteins in sugar beet}


The chloroplast thylakoid membrane is the main site for light reaction. Different crops were subjected to short-term low temperature treatment, and the changes in the protein abundance of photosynthetic system differed substantially. In wheat, the expression of $33 \mathrm{kDa}$ oxygen evolving complexes, oxygenevolving enhancer protein and light-harvesting complex protein were significantly repressed by low temperature treatment, while the expression of light-harvesting chlorophyll a/b binding protein was significantly up-regulated (Rinalducci et al. 2011; Herman et al. 2007). Interestingly, low temperature treatment in rice and barley resulted in a completely opposite expression profile for these proteins (Rinalducci et al. 2011; Hashimoto and Komatsu 2007). In this study, a total of 13 proteins involved in the light reaction were found to be significantly up-regulated after low temperature treatment for $24 \mathrm{~h}$. Seven proteins changed more than 2-fold, and two proteins were specifically expressed at low temperature treatment for $24 \mathrm{~h}$. These proteins involved multiple components of the light reaction, such as PS I, PS II, plastoquinone, and ATP synthase. In particular, the ATP synthase a subunit was up-regulated to 23-fold. A low temperature-induced protein that is involved in the light reaction could help to increase the supply of energy during photosynthesis and provide the necessary energy for the cold acclimation of sugar beet. In addition, it will help to maintain the balance between capability of light capture and consumption at continuous low temperatures. Similarly, after 2 weeks of cold acclimation at $4^{\circ} \mathrm{C}$, the chlorophyll fluorescence parameter $\mathrm{Fv} / \mathrm{Fm}$ of the $A$. thaliana seedlings remained $>0.8$, which was similar to the ratio at room temperature (Buer et al. 2016). The detection of various photosynthetic parameters showed that the net photosynthetic rate, stomatal conductance and chlorophyll fluorescence parameter were less affected during cold acclimation in winter wheat (Li et al. 2014).

\section{Effect of low temperature on chloroplast stroma proteins in sugar beet}

Chloroplast DNA primarily exists in the chloroplast stroma that contains the proteins involved in transcription and translation of chloroplast genomes. In addition, the region is also the main place of carbon assimilation and alkaloid metabolism. These proteins primarily participated in carbon metabolic pathways, such as the Calvin cycle, glycolysis, pentose metabolism and chloroplast protein synthesis and assembly process, based on a two-dimensional electrophoresis analysis of the chloroplast stroma proteome in $A$. thaliana (Peltier et al. 2006). Changes in the chloroplast proteome were analyzed in A. thaliana after low temperature treatment $24 \mathrm{~h}$ using DIGE techniques. The results indicated that 43 proteins are significantly expressed in chloroplast stroma, primarily RuBisCo, glyceraldehyde-3-phosphate dehydrogenase and 2-Cys antioxidant proteins (Goulas et al. 2006). Consistent with the results of this study, RuBisCo and 2-Cys antioxidant proteins were also found to be induced by low temperature. Glucose-6-phosphate dehydrogenase and 6-phosphogluconolactonase were also significantly downregulated after treatment with low temperature, suggesting that the pentose phosphate pathway was inhibited by low temperatures in sugar beet chloroplasts. Moreover, the proteins involved in starch metabolism changed significantly at low temperature. a-Glucan and water dikinase (BvGWD3) can catalyze the phosphorylation of the C3-position of starch, change the surface structure of starch granules, and further promote the cleavage of the glycosidic bond (Orzechowski et al. 2012). Isoamylase (BvISA3) can specifically recognize the a-1,6-glycosidic bond of amylopectin, thus promoting starch hydrolysis by causing the debranching of amylopectin (Delatte et al. 2006). Pullulanase (BvPU1), similar 
to isoamylase, can specifically recognize and hydrolyze the a-1,6-glycosidic linkages in amylopectin. Unlike BvISA3, BvPU1 regulates the synthesis of amylopectin by catalyzing the hydrolysis of the terminal branches of the amylopectin precursor (Streb et al. 2008). BvGWD3 and BvISA3 proteins were significantly down-regulated after low temperature treatment in the chloroplasts of sugar beet, while BvPU1 was specifically expressed. These results suggest that low temperature can inhibit the degradation of starch and induce the synthesis of amylopectin, therefore leading to the formation of starch grains in the chloroplast. The observation showed that a large amount of starch granules began to accumulate by transmission electron microscopy in the chloroplasts of paper mulberry (Broussonetia papyrifera) leaves after low temperature treatment for $24 \mathrm{~h}$. The transcriptome and proteome analyses led to the hypothesis that the accumulation of starch granules is an important mechanism for maintaining the Calvin cycle and photorespiration-mediated redox homeostasis in paper mulberry under low temperature conditions (Peng et al. 2015). In protein synthesis, the totals of three 50 S ribosomal proteins (BvRpl6, BvRpl21, and BvRpl31), one 30S ribosomal protein (BvRps17) and one $28 \mathrm{kDa}$ ribosomal protein were found to be significantly up-regulated by low temperature, indicating that the transcription and translation of chloroplast DNA closely relates to a low temperature response. A reverse genetics study found that ribosomal protein Rpl33 is not a necessary for plant growth in tobacco (Nicotiana tabacum L), but it is closely related to low temperature tolerance (Rogalski et al. 2008). The $\mathrm{Fv} / \mathrm{Fm}$ of rpl33 mutant decreased more quickly than that of wild type under low temperature stress, and the abundances of PsbD and PsaB proteins significantly decreased (Rogalski et al. 2008). In this study, a significant increase in ribosomal protein may contribute to promote the synthesis of photosystem proteins to form a dynamic balance with the damage to the proteins of photosystem and maintain normal photosynthesis in the chloroplasts of sugar beet under low temperature conditions.

\section{Effect of low temperature on the chloroplast envelope proteins in sugar beet}

A chloroplast envelope is composed of two layers of membrane at the edge of chloroplast, which is an important area to determine the entry and exit of water, ions, carbohydrates, proteins and other substances in the cytoplasm. In this study, 12 membrane transporters, including aquaporins, glucose transporters, ATP-binding cassette transporters and Toc-Tic complexes, were detected. These proteins are widely involved in the transport of carbohydrate, water, ATP, protein and other substance. The abundance changes in transporters will contribute to the establishment of new homeostasis in chloroplasts under low temperature conditions. Typically, the chloroplast proteome includes $>3,000$ proteins, of which only $3 \%-5 \%(80-100)$ proteins were derived from chloroplast genes (Fristedt 2017). Therefore, most chloroplast proteins need to cross the chloroplast envelope to be transported into chloroplasts to perform their functions after translation in the nuclear genome. The Toc-Tic complex is usually considered to be the primary transporter of chloroplast proteins. BVTIC20-v and BVTIC100 were significantly up-regulated and down-regulated after $24 \mathrm{~h}$ of low temperature treatment. The BN-PAGE results showed that AtTIC20-v and AtTIC100 are involved in the formation of different transport complexes in $A$. thaliana, respectively (Kikuchi et al. 2013). The changes in protein abundances of BvTIC20 and BVTIC100 identified in this study led to a hypothesis that the chloroplast of sugar beet selectively transported cytoplasmic proteins to the chloroplast in response to low temperature stress. Moreover, BvLTD was specifically expressed and 
can be used as an anchor protein to participate in the process of light-harvesting chlorophyll-binding proteins into the chloroplast under low temperature and transfer these proteins to the chloroplast signal recognition particle-mediated protein recognition transport pathway (Ouyang et al. 2011). These results suggest that the chloroplasts of sugar beet preferentially import photosystem-related proteins into chloroplasts to maintain normal photosynthesis by increasing the abundance of anchored proteins under low temperature stress. This is consistent with the significant increase of proteins involved in the light reaction detected in this study.

\section{Effects of low temperature on antioxidant proteins in chloroplasts}

The balance between light energy capture and light energy consumption can be destroyed by low temperature stress, and photosystem II overload leads to irreversible damage. In addition, low temperature stress can slow down the consumption of NADPH and accumulate electron acceptors in photosystem I ( $\left.\mathrm{NADP}^{+}\right)$by inhibiting enzyme activities in the Calvin cycle that eventually lead to electron transfer to oxygen molecules to generate ROS. The excessive accumulation of ROS can damage the cell membrane system, produce MDA and lead to the leakage of intracellular substances. The physiological responses of five wheat varieties to low temperature were measured, and the results showed that the contents of REL and MDA were higher during the overwintering period than those in the pre-wintering period (Zhang et al. 2016). After low temperature treatment at $8{ }^{\circ} \mathrm{C}$ for $4 \mathrm{~d}$, the contents of both REL and MDA increased to more than 2-fold of the original in cucumber leaves (Hu et al. 2006). Similar to the results of previous studies, the contents of REL and MDA also significantly increased in sugar beet leaves after low temperature $\left(4^{\circ} \mathrm{C}\right)$ treatment for $3 \mathrm{~d}$ and gradually increased with low temperature. These results showed that continuous low temperature can produce photoinhibition in sugar beet seedlings. To alleviate the oxidative damage caused by low temperatures, plants have evolved multiple antioxidant pathways. SOD can catalyze superoxide anion radicals to produce $\mathrm{H}_{2} \mathrm{O}_{2}$ and $\mathrm{O}_{2}$ that are primarily divided into three types based on their different auxiliary functions, namely $\mathrm{Cu} / \mathrm{Zn}-\mathrm{SOD}$, Fe-SOD and Mn-SOD, and $\mathrm{Cu} / \mathrm{Zn}$-SOD is primarily distributed in chloroplasts (Han et al. 2020). BvCu/Zn-SOD proteins were significantly induced by low temperature. The $\mathrm{H}_{2} \mathrm{O}_{2}$ generated by SOD can be further degraded by CAT and peroxidase, so as to scavenge ROS. Similarly, BvCAT is also induced by low temperature. The ascorbic acid-glutathione cycle is considered to be the most important pathway for plants to scavenge ROS, which is widely found in chloroplasts, cytoplasm, mitochondria and peroxides. Water and monodehydroascorbic acid (MDHA) are produced by the reduction of ascorbic acid and hydrogen peroxide under the catalysis of ascorbic acid peroxidase, and some MDHAs are converted further into dehydroascorbic acid (DHA). Subsequently, MDHA generates ascorbic acid under the action of monodehydroascorbate reductase. In addition, DHA and GSH generate ascorbic acid and glutathione disulfide (GSSG) under the action of dehydroascorbate reductase. Finally, GSSG produces GSH owing to the activities of glutathione reductase (Yaohui et al. 2019). However, this study did not detect any significant changes in these proteins induced by low temperature. In contrast, thiol peroxidases (Prx) and thioredoxin ( $\operatorname{Trx}$ ), such as 1-Cys and 2-Cys peroxidases, were detected to be significantly up-regulated by low temperature. With the exception of the degradation of $\mathrm{H}_{2} \mathrm{O}_{2}$, Prx and Trx are involved in the oxidative 
modification of $\mathrm{H}_{2} \mathrm{O}_{2}$ signaling proteins in three ways (Netto and Antunes 2016). First, Prx can indirectly interfere with $\mathrm{H}_{2} \mathrm{O}_{2}$ and direct oxidation of the signal protein by regulating the concentration of intracellular $\mathrm{H}_{2} \mathrm{O}_{2}$. Secondly, $\operatorname{Prx}$ can catalyze the oxidation of signal proteins during the degradation of $\mathrm{H}_{2} \mathrm{O}_{2}$. Finally, the Prx oxidized by $\mathrm{H}_{2} \mathrm{O}_{2}$ makes a signal protein that is oxidized under the action of $\operatorname{Trx}$ (Netto and Antunes 2016). The results of this study suggest that the low temperature-induced expression of Prx and Trx can further induce the expression of resistance-related genes by activating the $\mathrm{H}_{2} \mathrm{O}_{2}$ signaling pathway in chloroplasts of sugar beet, and further enhance the cold acclimation.

\section{Conclusions}

This study preliminarily explored the mechanisms of response of sugar beet chloroplasts and identified some important chloroplast proteins in response to low temperature stress. Four pathways of cold acclimation in the responses of sugar beet to low temperature were analyzed, which can be used to guide subsequent research. In this experiment, we found that the Toc-Tic complex could preferentially import photosynthesis-related proteins into chloroplasts under the control of BVLTD, so as to maintain the photosynthesis of sugar beet at low temperature. In addition, Prx and Trx can also be induced to activate the $\mathrm{H}_{2} \mathrm{O}_{2}$ pathway by low temperature, induce the expression of resistance genes, and enhance the cold acclimation of sugar beet. These two points can be used as the key contents of a follow-up study that could provide direction to screen cold-resistant genes in sugar beet and have important significance for the cold-resistant breeding of this crop.

\section{Abbreviations}

Chl: Chlorophyll; REL: relative conductivity; MDA: malondialdehyde; SOD: superoxide dismutase; DREB: dehydration responsive element binding protein; DEPs: differentially expressed proteins; Prx: peroxiredoxin; Trx: thioredoxin; ROS: reactive oxygen species; PBS: phosphate-buffered saline; FA: formic acid; LC-MS: liquid chromatography-mass spectrometry; GO: gene ontology; PS I: photosystem I; PS II: photosystem II MDHA: monodehydroascorbic acid; DHA: dehydroascorbic acid

\section{Declarations}

\section{Authors'contributions}

ZP and FSZ conceived and designed the experiment. WJL, JLL, JPS and YZ performed the experiments. ZP, ZDW, WX and YGW analysed the data. JLL wrote the manuscript. All authors read and approved the final manuscript.

\section{Funding}

This study was supported by grants from the Natural Science Foundation of Heilongjiang Province of China (LH2021C074); the National Natural Science Foundation of China (32101765); the earmarked fund 
for China Agriculture Research System; the Foundation for Innovative Young Talents in Higher Education of Heilongjiang Province (UNPYSCT-2020014); the Scientific Research Foundation of the Higher Education Institutions of Heilongjiang Province (KJCX201920).

\section{Availability of data and materials}

The data used and analyzed in this study can be provided from the corresponding author for scientific, non-profit purpose.

\section{Ethics approval and consent to participate}

Not applicable.

\section{Consent for publication}

Not applicable.

\section{Competing interests}

The authors declare that they have no competing interests.

\section{References}

1. Agrawal GK, Rakwal R, Yonekura M, Kubo A (2015) Proteome analysis of differentially displayed proteins as a tool for investigating ozone stress in rice (Oryza sativa $L$.) seedlings. Proteomics 2(8):947-959.

2. An D, Yang J, Zhang P (2012) Transcriptome profiling of low temperature-treated cassava apical shoots showed dynamic responses of tropical plant to cold stress. BMC Genomics 13(1):1-25.

3. Bao G, He F, Chen W, Sun J, Ding X (2020) Physiological effects of different concentrations of chloride deicing salt and freeze-thaw stress on Secale cereale L. seedlings. Journal of Plant Growth Regulation 39:15-25.

4. Bo H, Guo J, Yuan L (2007) Molecular cloning and functional characterization of a DREB1/CBF-like gene (GhDREB1L) from cotton. Science in China 50:7-14.

5. Boyce K, Sievers F, Higgins DG (2015) Instability in progressive multiple sequence alignment algorithms. Algorithms for Molecular Biology 10(1):1-10.

6. Buer JV, Cvetkovic J, Baier M (2016) Cold regulation of plastid ascorbate peroxidases serves as a priming hub controlling ROS signaling in Arabidopsis thaliana. BMC Plant Biology 16(1):1-20.

7. Calzadilla PI, Vilas JM, Escaray FJ, Unrein F, Carrasco P, Ruiz OA (2019) The increase of photosynthetic carbon assimilation as a mechanism of adaptation to low temperature in Lotus japonicus. Scientific Reports 9:863.

8. Cao HX, Sun CX, Shao HB, Lei XT (2011) Effects of low temperature and drought on the physiological and growth changes in oil palm seedlings. African Journal of Biotechnology 
10(14):2630-2637.

9. Coleman O, Henry M, Clynes M, Meleady P (2017) Filter-aided sample preparation (FASP) for improved proteome analysis of recombinant chinese hamster ovary cells. Methods in Molecular Biology 1603:187-194.

10. Delatte T, Umhang M, Trevisan M, Eicke S, Thorneycroft D, Smith SM, Zeeman SC (2006) Evidence for distinct mechanisms of starch granule breakdown in plants. Journal of Biological Chemistry 281(17):12050-12059.

11. Du Z, Xin Z, Yi L, Zhang Z, Zhen S (2010) Agrigo: A Go analysis toolkit for the agricultural community. Nucleic Acids Research 38 (Web Server issue): W64-70.

12. FargašováA, Molnárová M (2010) Assessment of $\mathrm{Cr}$ and Ni phytotoxicity from cutlery-washing waste-waters using biomass and chlorophyll production tests on mustard Sinapis alba L. seedlings. Environmental Science and Pollution Research 17(1):187-194.

13. Farnsworth N, Bensard C, Bryant SJ (2012) The role of the PCM in reducing oxidative stress induced by radical initiated photoencapsulation of chondrocytes in poly (ethylene glycol) hydrogels. Osteoarthritis and Cartilage 20:1326-1335.

14. Fristedt, R (2017) Chloroplast function revealed through analysis of GreenCut2 genes. Journal of Experimental Botany 68(9):2111-2120.

15. Gan P, Liu F, Li R, Wang S, Luo J (2019) Chloroplasts-beyond energy capture and carbon fixation: tuning of photosynthesis in response to chilling stress. International Journal of Molecular Sciences 20(20):5046-5060.

16. Gerber L, Kress JC, Imek P, Berkova P, Overgaard J (2021) Cold acclimation preserves hindgut reabsorption capacity at low temperature in a chill-susceptible insect, Locusta migratoria. Comparative Biochemistry and Physiology-Part A Molecular \& Integrative Physiology 252:110850. doi:10.1016/j.cbpa.2020.110850

17. Goulas E, Schubert M, Kieselbach T, Kleczkowski LA, Gardestrom P, Schroder W, Hurry V (2006) The chloroplast lumen and stromal proteomes of Arabidopsis thaliana show differential sensitivity to short-and long-term exposure to low temperature. Plant Journal 47:720-734.

18. Han LM, Hua WP, Cao XY, Yan JA, Chen C, Wang ZZ (2020) Genome-wide identification and expression analysis of the superoxide dismutase (SOD) gene family in Salvia miltiorrhiza. Gene 742:144603. doi:10.1016/j.gene.2020.144603.

19. Hashimoto M, Komatsu S (2007) Proteomic analysis of rice seedlings during cold stress. Proteomics 7(8):1293-1302.

20. Herman EM, Rotter K, Premakumar R, Elwinger G, Bae R, Ehler-King L, Chen S, Livingston DP (2006) Additional freeze hardiness in wheat acquired by exposure to $-3{ }^{\circ} \mathrm{C}$ is associated with extensive physiological, morphological, and molecular changes. Journal of Experimental Botany 57(14):36013618.

21. Hu WH, Shi K, Song XS, Xia XJ, Zhou YH, Yu JQ (2006) Different effects of chilling on respiration in leaves and roots of cucumber (Cucumis sativus). Plant Physiology \& Biochemistry Ppb 44(11- 
12):837-843.

22. Kaya MD, Kulan EG (2020) Effective seed priming methods improving germination and emergence of sugar beet under low-temperature stress. Sugar Tech 22:1086-1091.

23. Kenchanmane Raju SK, Barnes AC, Schnable JC, Roston RL (2018) Low-temperature tolerance in land plants: Are transcript and membrane responses conserved?. Plant Science 276:73-86.

24. Kikuchi S, BeDard J, Hirano M, Hirabayashi Y, Oishi M, Imai M, Takase M, Ide T, Nakai M (2013) Uncovering the protein translocon at the chloroplast inner envelope membrane. Science 339(6119):571-574.

25. Kočová M, Holá D, Wilhelmová N, Rothová O (2009) The influence of low-temperature on the photochemical activity of chloroplasts and activity of antioxidant enzymes in maize leaves. Biologia Plantarum 53(3):475-483.

26. Li X, Cai J, Liu F, Dai T, Cao W, Jiang D (2014) Cold priming drives the sub-cellular antioxidant systems to protect photosynthetic electron transport against subsequent low temperature stress in winter wheat. Plant Physiol Biochem 82:34-43.

27. Liu C, Yang X, Yan Z, Fan Y, Feng G, Liu D (2019) Analysis of differential gene expression in coldtolerant vs. cold-sensitive varieties of snap bean (Phaseolus vulgaris $L$.) in response to low temperature stress. Genes Genomics 41:1445-1455.

28. Micallef $L$, Rodgers $P$ (2014) eulerAPE: Drawing area-proportional 3-venn diagrams using ellipses. PLoS One 9(7): e101717. doi: 10.1371/journal.pone.0101717

29. Minh BQ, Schmidt H, Chernomor O, Schrempf D, Woodhams M, Haeseler A, Lanfear R (2020) IQ-TREE 2: New models and efficient methods for phylogenetic inference in the genomic era. Molecular Biology and Evolution 37:1530-1534.

30. Moliterni VMC, Paris R, Onofri C, Orru L, Cattivelli L, Pacifico D, Avanzato C, Ferrarini A, Delledonne M, Mandolino G (2015) Early transcriptional changes in Beta vulgaris in response to low temperature. Planta 242:187-201.

31. Mutasa-Gottgens ES, Joshi A, Holmes HF, Hedden P, Göttgens B (2012) A new RNASeq-based reference transcriptome for sugar beet and its application in transcriptome-scale analysis of vernalization and gibberellin responses. BMC Genomics 13(1):99.

32. Netto L, Antunes $F$ (2016) The roles of peroxiredoxin and thioredoxin in hydrogen peroxide sensing and in signal transduction. Molecules \& Cells 39(1):65-71.

33. Orzechowski S, Grabowska A, Sitnicka D, Siminska J, Felus M, Dudkiewicz M, Fudali S, Sobczak M (2013) Analysis of the expression, subcellular and tissue localisation of phosphoglucan, water dikinase (PWD/GWD3) in Solanum tuberosum L.: a bioinformatics approach for the comparative analysis of two a-glucan, water dikinases (GWDs) from Solanum tuberosum L. Acta Physiologiae Plantarum, 35:483-500.

34. Ouyang M, Li X, Ma J, Chi W, Xiao J, Zou M, Chen F, Lu C, Zhang L (2011) LTD is a protein required for sorting light-harvesting chlorophyll-binding proteins to the chloroplast SRP pathway. Nature Communications 2:277. 
35. Peltier JB, Yang C, Qi S, Zabrouskov V, Giacomelli L, Rudella A, Ytterberg AJ, Rutschow H, Wijk KJV (2006) The oligomeric stromal proteome of Arabidopsis thaliana chloroplasts. Molecular \& Cellular Proteomics 5(1):114-133.

36. Peng X, Teng L, Yan X, Zhao M, Shen S (215) The cold responsive mechanism of the paper mulberry: decreased photosynthesis capacity and increased starch accumulation. BMC Genomics 16(1):898.

37. Pi Z, Xing W, Zhu X, Long J, Zou Y, Wu Z (2020) Temporal expression pattern of bolting-related genes during vernalization in sugar beet. Sugar Tech 23:146-157.

38. Popov VN, Astakhova NV (2021) Ultrastructural changes in chloroplasts of Cucumis sativus L. and Secale cereale L. during low-temperature hardening. Russian Journal of Plant Physiology 68(4):678687.

39. Porcel R, Bustamante A, Ros R, Serrano R, Mulet Salort JM (2018) BvCOLD1: A novel aquaporin from sugar beet (Beta vulgaris $L$.) involved in boron homeostasis and abiotic stress. Plant Cell \& Environment 41:2844-2857.

40. Rinalducci S, Egidi MG, Mahfoozi S, Godehkahriz SJ, Zolla L (2011) The influence of temperature on plant development in a vernalization-requiring winter wheat: A 2-DE based proteomic investigation. Journal of Proteomics 74(5):643-659.

41. Rogalski M, Schottler MA, Thiele W, Schulze WX (2008) Rpl33, a nonessential plastid-encoded ribosomal protein in tobacco, is required under cold stress conditions. Plant Cell 20(8):2221-2237.

42. Streb S, Delatte T, Umhang M, Eicke S, Schorderet M, Reinhardt D, Zeeman SC (2008) Starch granule biosynthesis in Arabidopsis is abolished by removal of all debranching enzymes but restored by the subsequent removal of an endoamylase. Plant Cell 20(12):3448-3466.

43. Wang M, Zhang T, Peng H, Luo S, Tan J, Jiang K, Heng Y, Zhang X, Guo X, Zheng J, Cheng Z (2018) Rice premature leaf senescence 2 , encoding a glycosyltransferase (GT), is involved in leaf senescence. Frontiers in Plant Science 9:560.

44. Wang Y, Peng C, Zhan Y, Yu L, Li M, Li J, Geng G (2017) Comparative proteomic analysis of two sugar beet cultivars with contrasting drought tolerance. Journal of Plant Growth Regulation 36(3):113.

45. Wen X, Zhang X, Hu Y, Xu J, Wang T, Yin S (2019) iTRAQ-based quantitative proteomic analysis of Takifugu fasciatus liver in response to low-temperature stress. Journal of Proteomics 201:27-36.

46. Wu Y, Jiang L, Ning G, Chu L, Liu W, Wang Y, Zhao Y (2019) A sensitive and simple impedance sensing strategy for glutathione and glutathione reductase activity detection. Journal of Analytical Chemistry 74(5):505-512.

47. Xing W, Pi Z, Liu J, Li X, Zou Y, Wang M, Liu D, Wang Q, Wu Z (2020) Comparative transcriptome analysis reveals an ABA-responsive regulation network associated with cell wall organization and oxidation reduction in sugar beet. Plant Growth Regulation 91:127-141.

48. Yang L, Zhang Y, Zhu N, Koh J, Ma C, Yu P, Yu B, Chen S, Li H (2013) Proteomic analysis of salt tolerance in sugar beet monosomic addition line M14. Journal of Proteome Research 12(11):49314950 . 
49. Zhang B, Jia D, Gao Z, Dong Q, He L (2016) Physiological responses to low temperature in spring and winter wheat varieties. Journal of the Science of Food \& Agriculture 96(6):1967-1973.

50. Zhang H, Gao S, Lercher M, Hu S, Chen W (2012) EvolView, an online tool for visualizing, annotating and managing phylogenetic trees. Nucleic Acids Research 40 (Web Server issue): W569-572.

51. Zhao C, Zhang Z, Xie S, Si T, Li Y, Zhu JK (2016) Mutational evidence for the critical role of CBF transcription factors in cold acclimation in Arabidopsis. Plant Physiology 171:2744-2759.

\section{Figures}
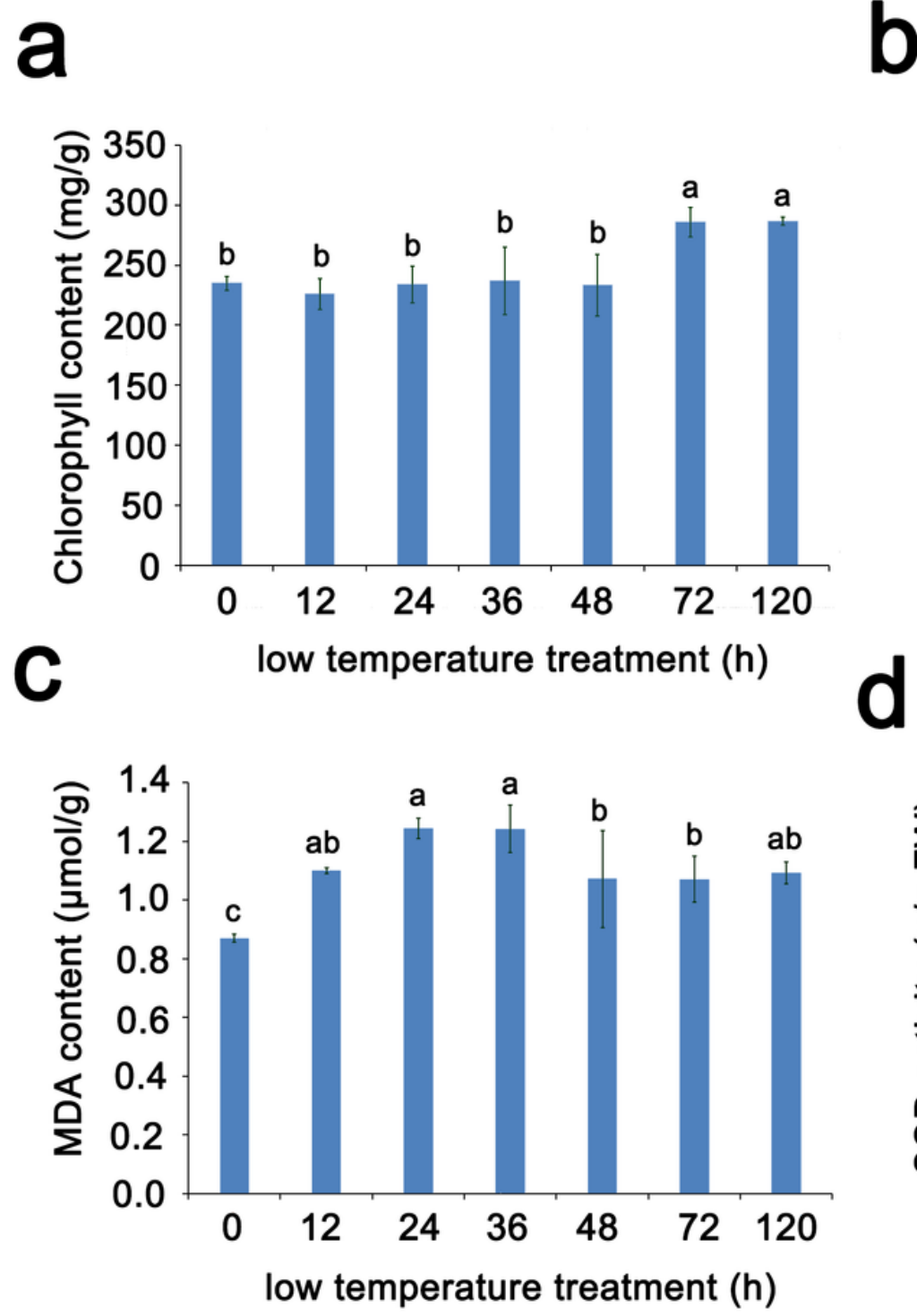

b
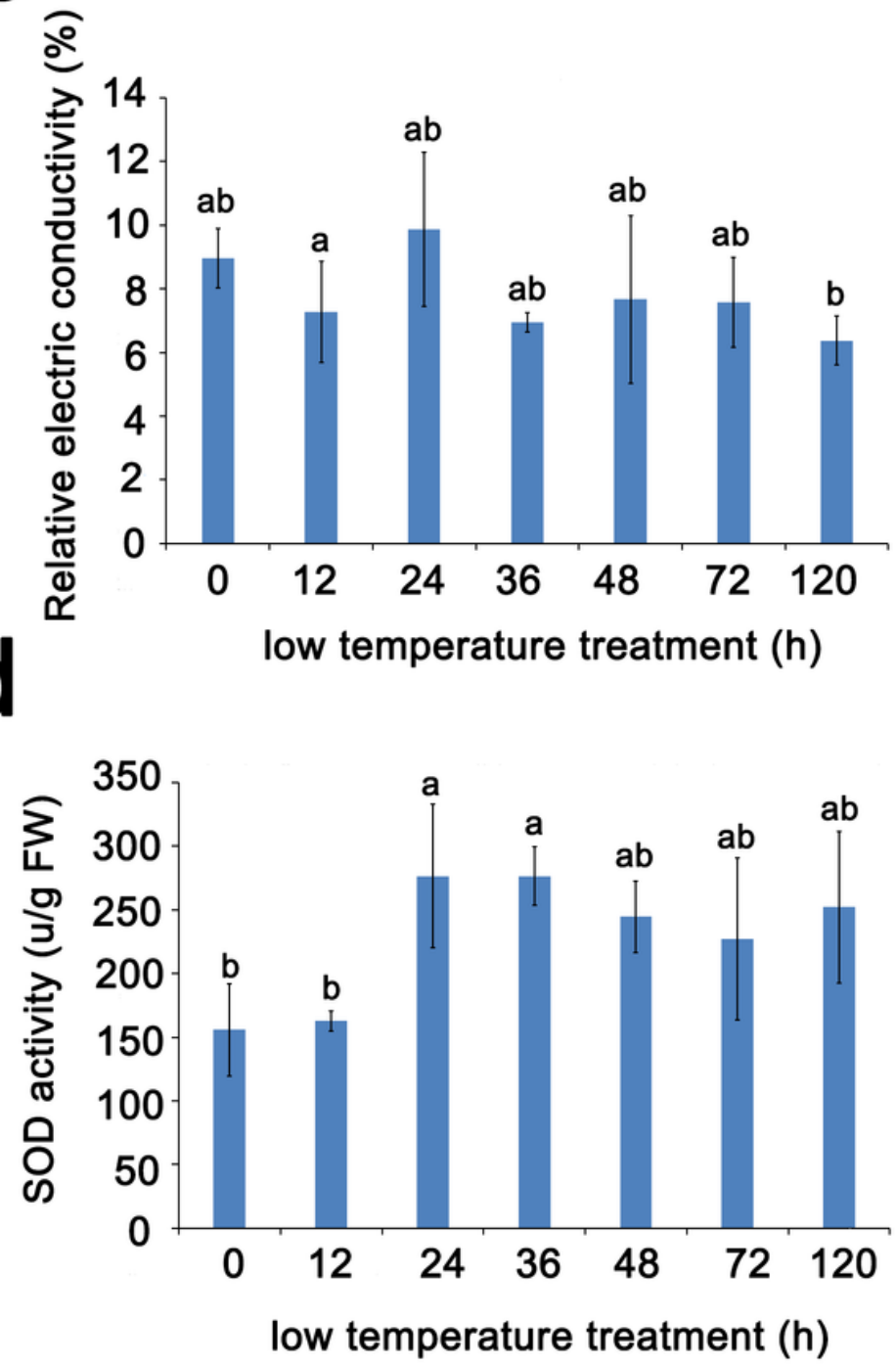

Figure 1

Effect of low temperature $\left(4^{\circ} \mathrm{C}\right)$ on malondialdehyde (MDA), relative electrical conductivity (REL), chlorophyll and superoxide dismutase (SOD) in sugar beet Lowercase letters represent the significant level of $\mathrm{P}<0.05$ between different treatments 


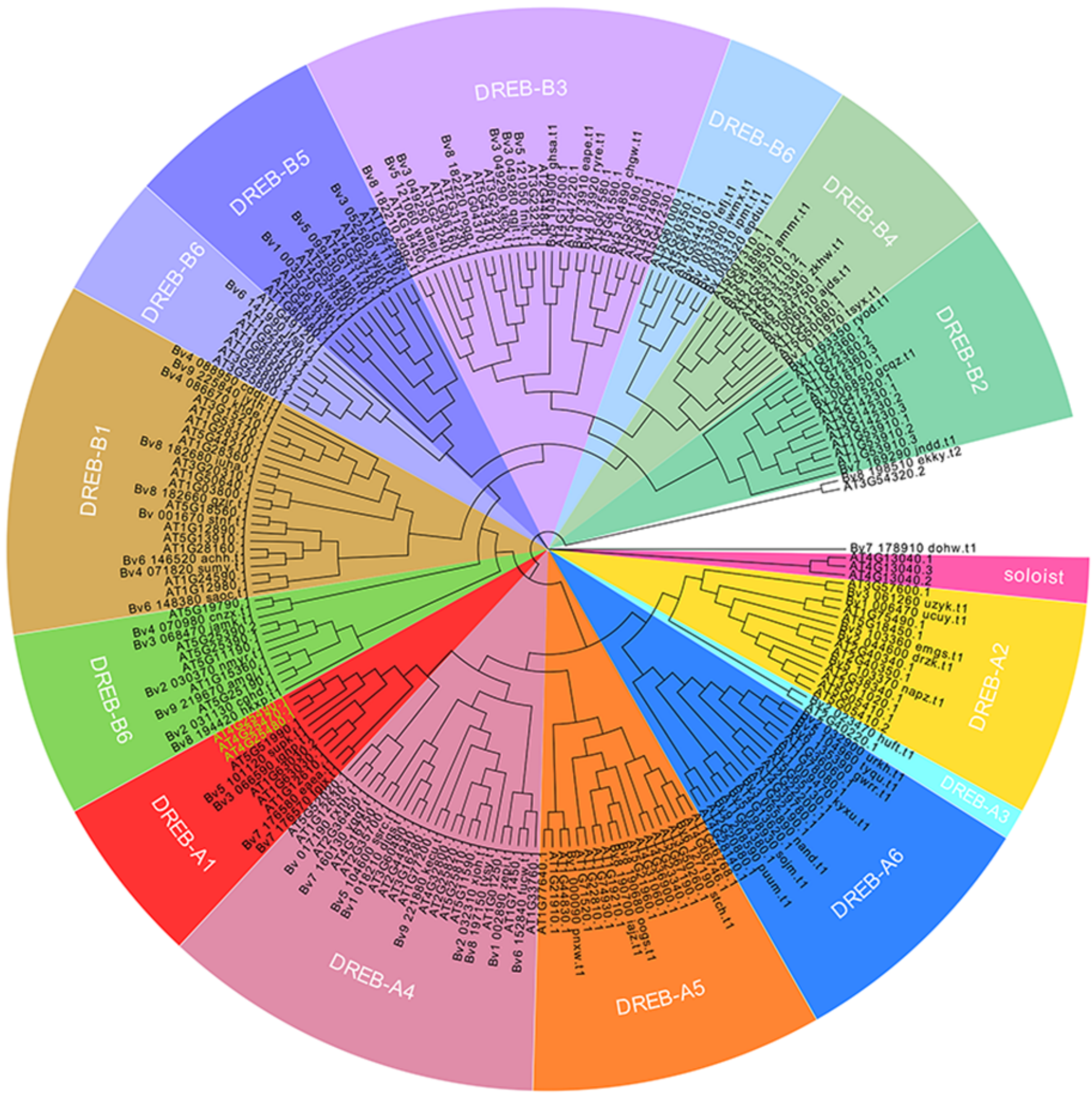

Figure 2

Phylogenetic analysis of the DREB family in sugar beet. Different background colors indicate different subfamilies, while the green letters in DREB-A1 are AtDREB1A, AtDREB1B and AtDREB1C, respectively. 
a

$F P K M(\log 10))^{-2}-1 \quad 0 \quad 1,2$
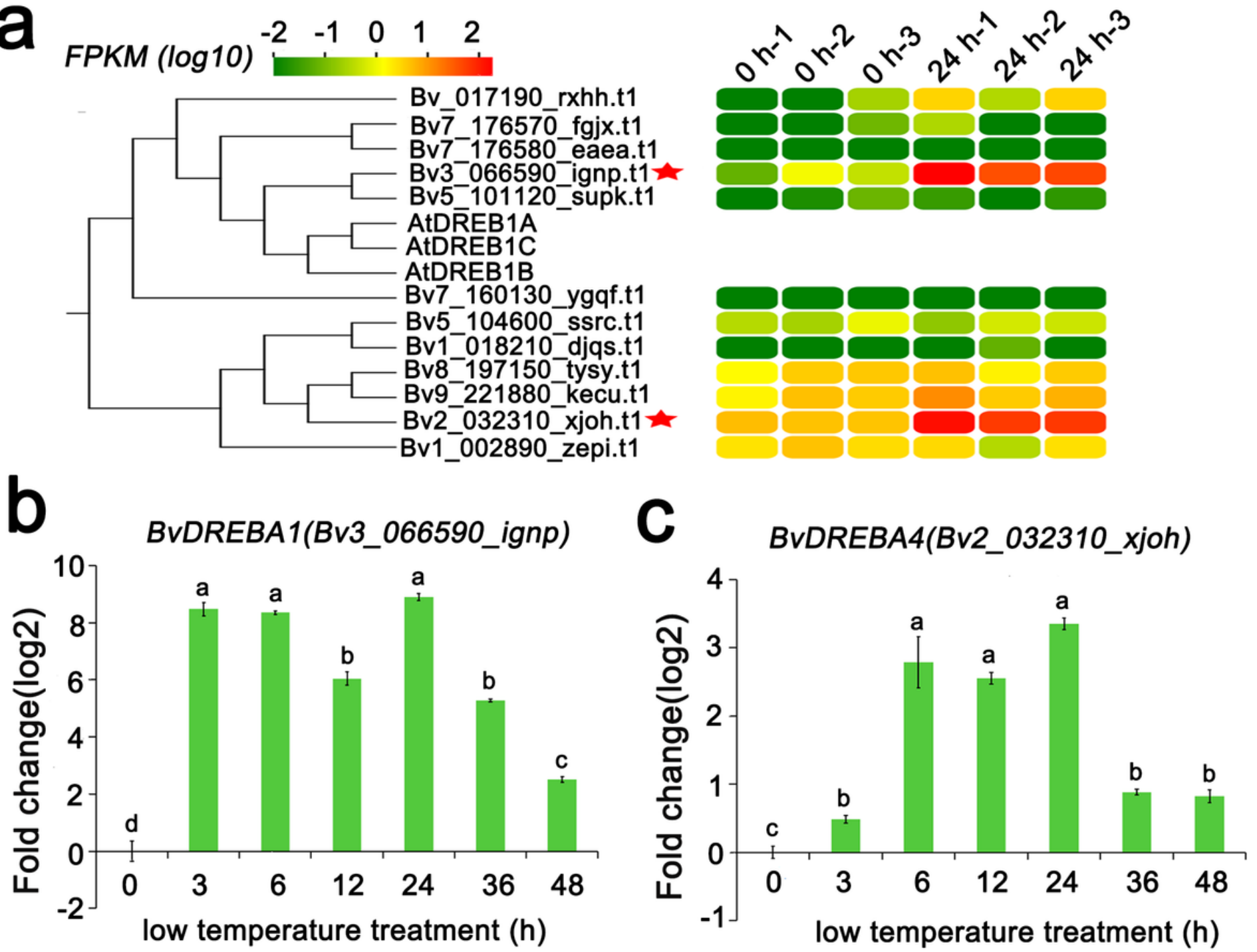

Figure 3

The patterns of expression of BvDREBA1 and BvDREBA4 (a) Transcriptome analysis of gene expression of BvDREBA1 and BvDREBA4 at low temperature $\left(4^{\circ} \mathrm{C}\right)(\mathrm{b})$ The pattern of expression of BvDREBA1 in response to low temperature $\left(4^{\circ} \mathrm{C}\right)$ (c) The pattern of expression of BvDREBA4 in response to low temperature $\left(4^{\circ} \mathrm{C}\right)$ Different letters represent significant levels of $\mathrm{P}<0.05$ between different low temperature treatments 


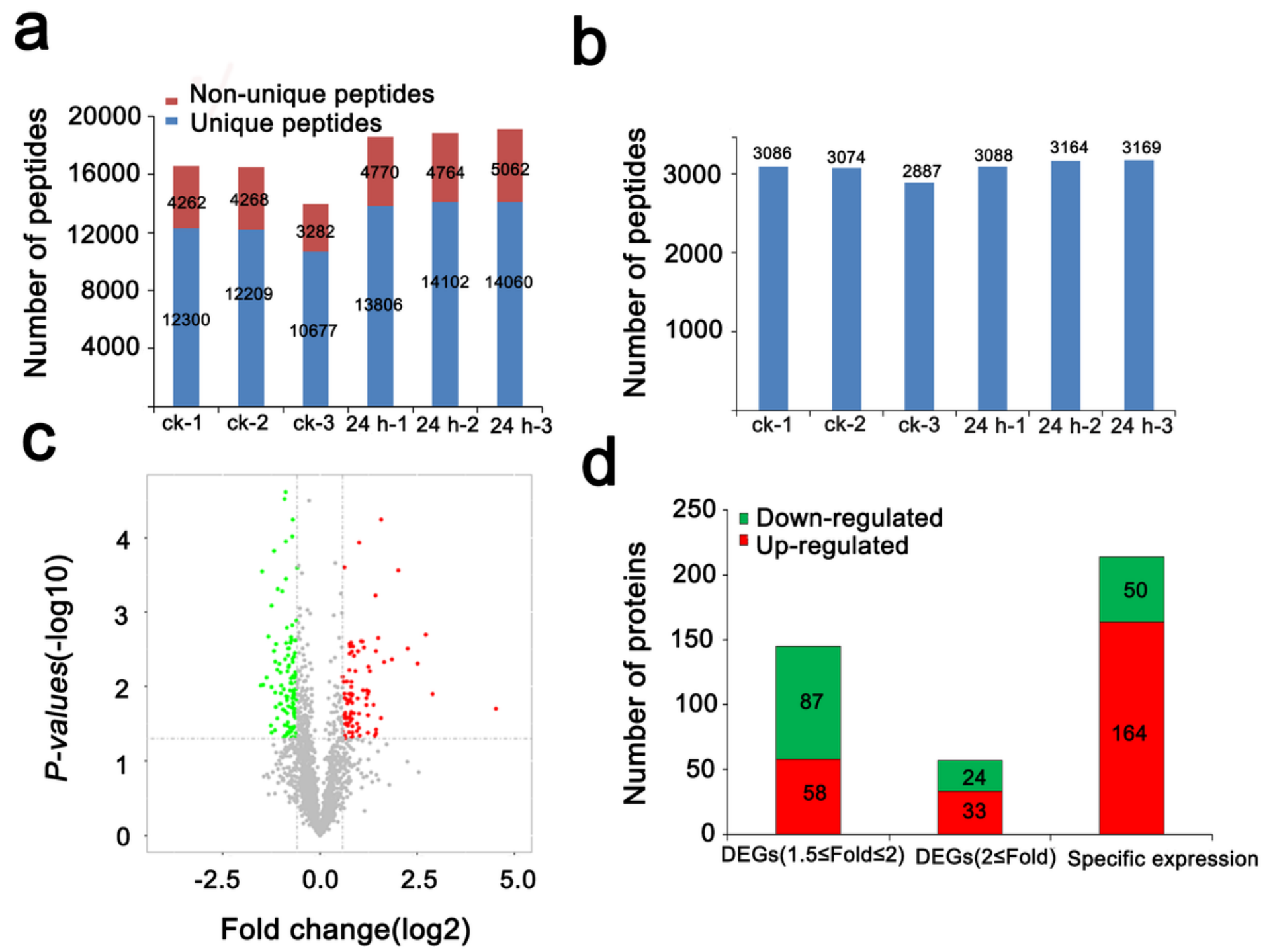

Figure 4

Statistics of protein identification results (a) The number of peptides identified by LC-MS/MS (b) The number of proteins identified by LC-MS/MS (c) The volcano plot of the proteins identified in the CK and treatment $(d)$ The number of up- and down-regulated proteins 


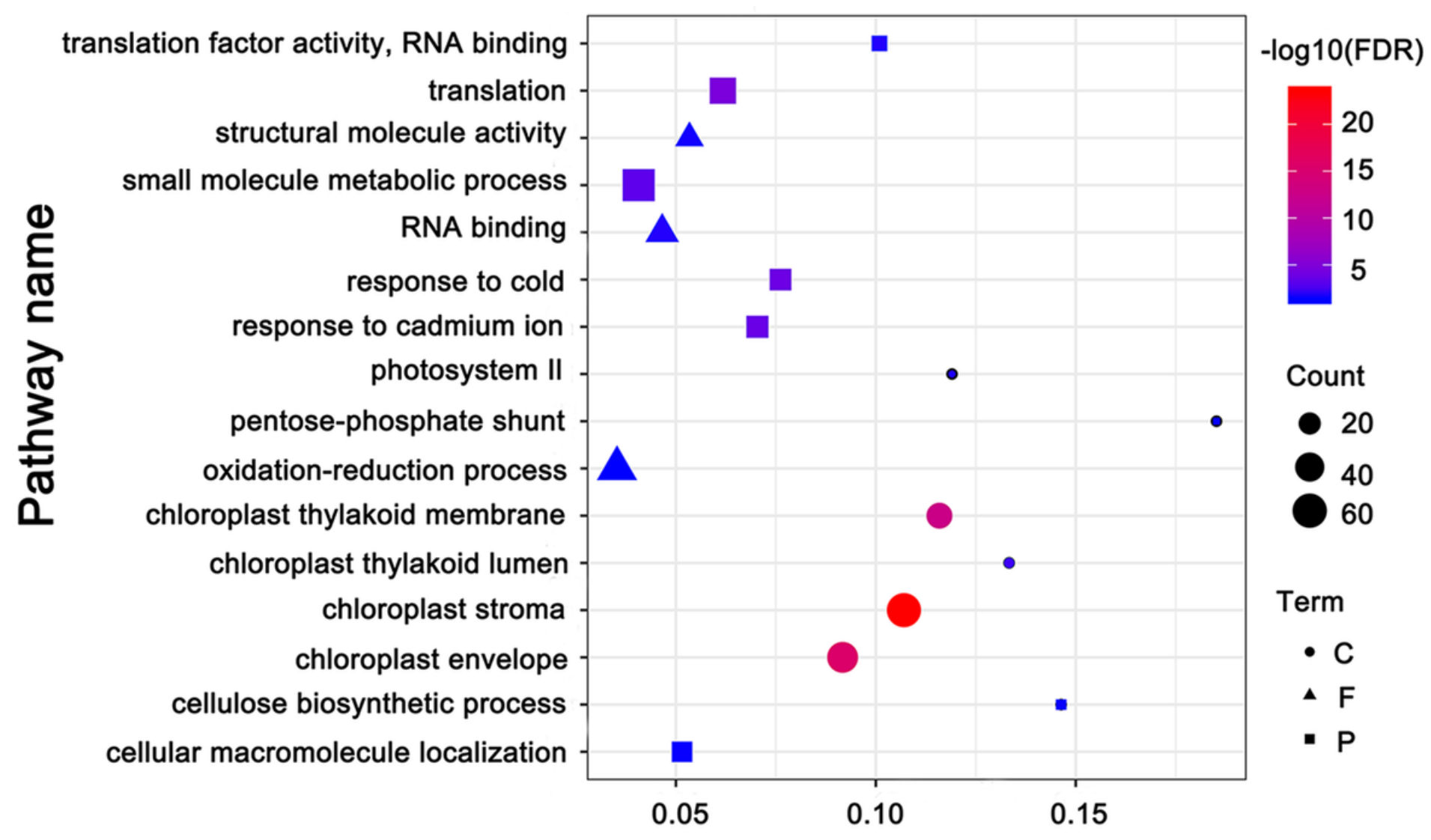

Rich factor

Figure 5

enrichment of significantly differentially expressed proteins 

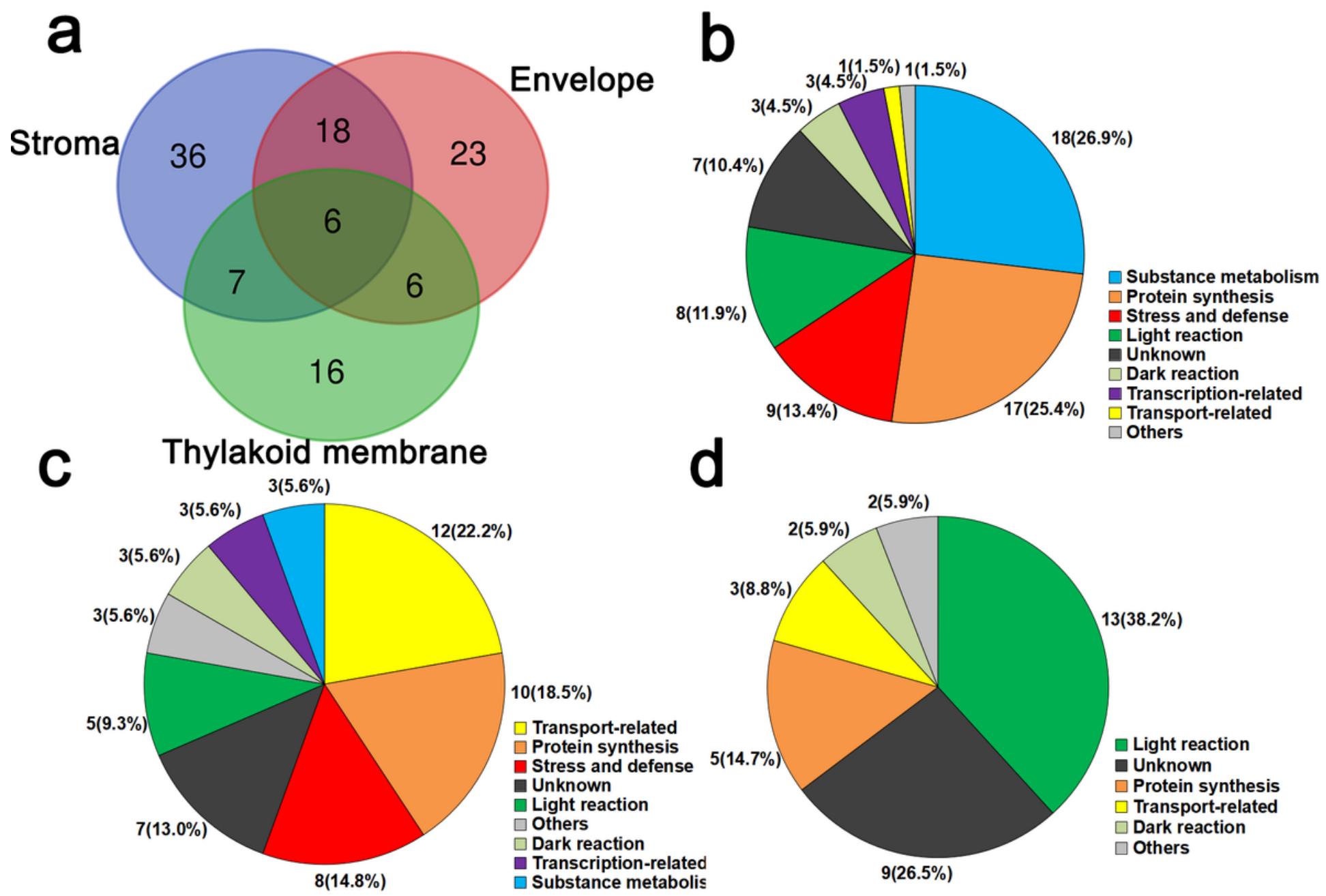

\section{Figure 6}

Functional annotation of differential expressed proteins in different subchloroplast fractions (a) Venn diagram (b) Chloroplast stroma (c) Chloroplast envelope (d) Chloroplast thylakoid membrane 


\section{Chilling}

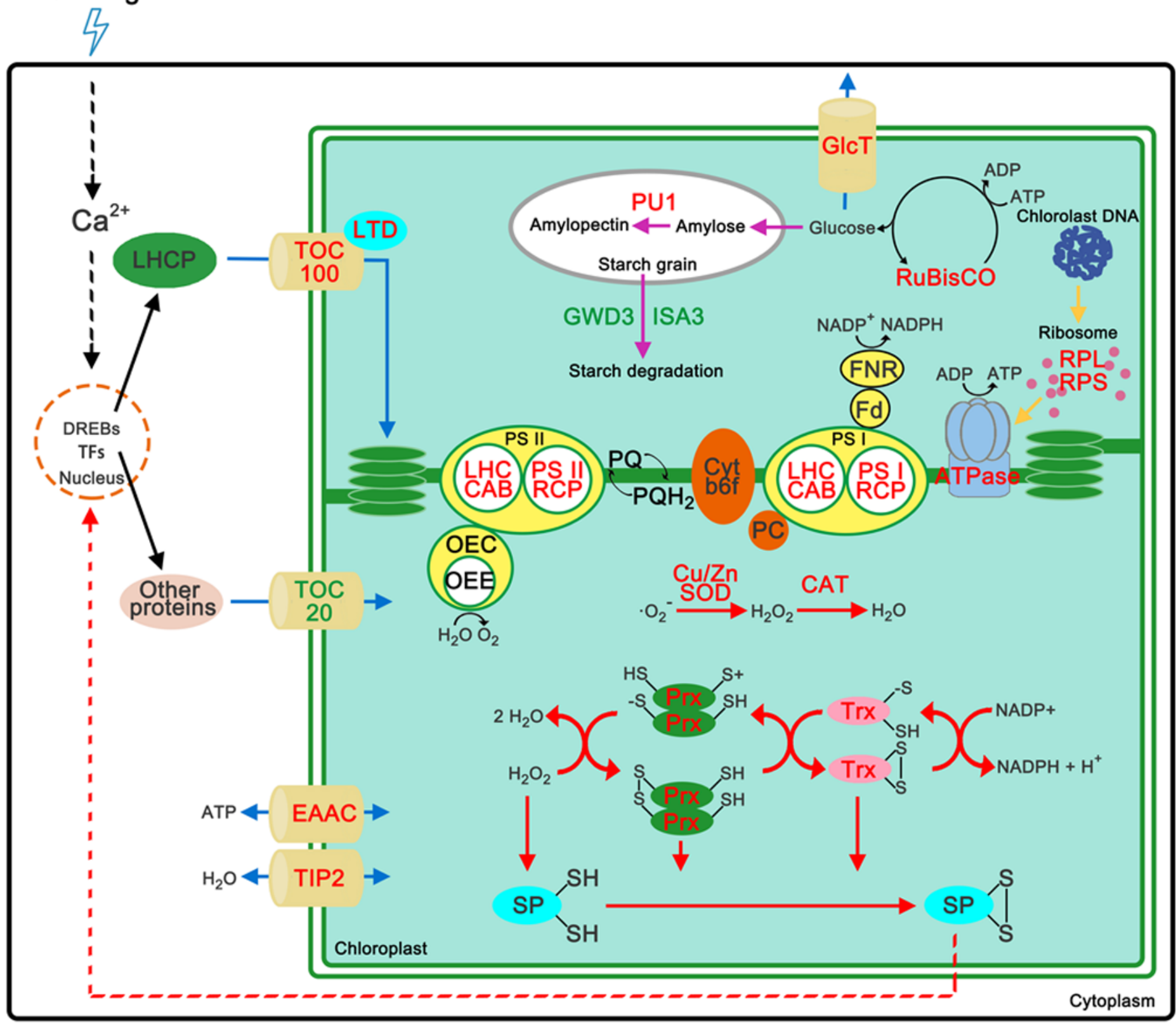

Figure 7

Schematic presentation of systematic chilling response mechanisms in chloroplast of sugar beet Red and green letters represent proteins were significantly up- and down-regulated after chilling, respectively. Blue, red, yellow and purple arrows represent transport-related pathway, antioxidant pathway and $\mathrm{H} 2 \mathrm{O} 2$ signal, translation from chloroplast DNA and starch metabolism, respectively. The dotted line represents the signal transduction pathway.

\section{Supplementary Files}

This is a list of supplementary files associated with this preprint. Click to download. 
- TableS1.xIsx

- Tables2.xIsx

- Fig.S1.tif

- Fig.S2.tif 